\section{Executive Board: AGM2011 report}

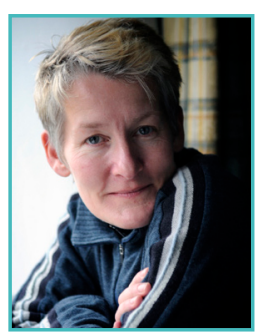

\section{Teresa K Attwood}

Faculty of Life Sciences and School of Computer Science, University of Manchester, Machester, UK

\section{Commitee members \\ Chair: $\quad$ Teresa K Attwood \\ Secretary: $\quad$ Andreas Gisel \\ Treasurer: Etienne de Villiers \\ Member: $\quad$ Erik Bongcam-Rudloff}

Since the last Annual General Meeting (AGM), the Executive Board (EB) has continued to meet regularly and to convene monthly video meetings for general discussion of issues relating to the Project Committees (PCs), to EMBnet.journal, to the website, etc.; the meetings have also allowed us to discuss matters relating to the Stichting accounts, and to prepare the groundwork for this year's AGM.

The monthly video meetings are open to all members of the EMBnet constituency, and those who've attended will appreciate the significant technical issues we've experienced with the platforms used to host them; needless to say, we're striving to find the best solution to these ongoing problems, but meanwhile encourage participation and greater involvement with our activities - despite the technical irritations, there's a lot going on!

This time last year, the EB had been in office for a relatively short time and most of its members were new. The incoming EB therefore faced a steep learning curve, at a time when the global bioinformatics landscape was also clearly in a state of flux. We therefore wanted to use the 2010 AGM as an opportunity to examine those changes, to reflect on EMBnet's position, and to explore its aspirations and motivations moving forward. Recognising the need for both structural and behavioural changes within EMBnet, the idea was to take some practical steps towards trying to make the daily business of EMBnet run

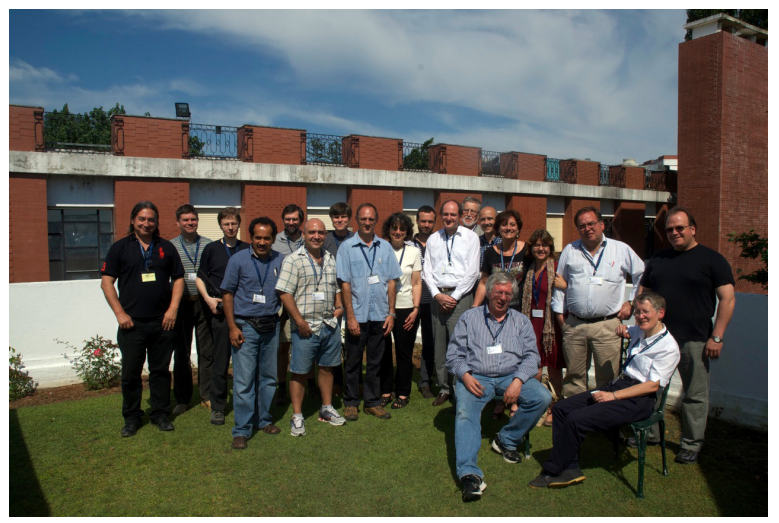

Figure 1. EMBnet members during the AGM in Oeiras, Portugal.

more efficiently, to engage more of its members in the activities of the PCs, and to start to improve the EMBnet 'brand'. Specifically, we hoped to be able to establish internal mechanisms by which we might: i) secure strategic alliances with other organisations; ii) compete more strategically for funding for some of our activities; and iii) promote our activities more effectively. Ultimately, our goal was to facilitate the evolution of EMBnet into a respected network of bioinformatics professionals.

Today, our work towards seeding these ambitions is beginning to bear fruit, and the successes we have to report are a testament to our increasing professionalism and the respect this is garnering outside the EMBnet community. A year on, we've managed to i) establish a formal alliance with the ISCB in the field of education [ISCB Press Release']; ii) win funds to underpin a training and visitor exchange programme around the theme of NGS data analysis (this is the SeqAhead ${ }^{2}$ COST Action); iii) introduce EMBnet.digest ${ }^{3}$, a lightweight monthly flyer for disseminating some of EMBnet's key activities and success stories; and iv) work with the PCs both to develop a professional EMBnet exhibition stand and to upgrade and migrate the www.embnet.org Drupal CMS to the new Linux server in Norway. This year's AGM aims to build on these foundations, to actively engage all members in: developing content and graphics for the new Drupal website; evaluating the e-learning site and outlining strategies for its "rebirth"; updating the content of the EMBnet.journal website;

1 http://journal.embnet.org/index.php/embnetjournal/article/view/217/477

2 http://www.segahead.eu

3 http://www.embnet.org/EMBnet.digest 
and developing new Quick Guides, etc., as time permits. We also plan to use the AGM as an opportunity to formulate concrete resolutions on EMBnet's internal structure, membership and alliances, and on its policies and mechanisms for sponsorship and fund raising.

Given the transitional period of the last 18 months or so, we considered it important to try to maintain a degree of stability within the EB. Therefore, at the forthcoming AGM, we propose to make no changes, in order to allow the current team both to build on the demonstrable progress we've made during these challenging times, to deliver more on the plans we outlined last year, and to take EMBnet forward by embracing new partners and new activities. There's clearly a lot more to do, and we therefore call on all of you to help us realise our collective ambitions for the most widely distributed and oldest bioinformatics network in the world - a network of which we should rightly be proud! 